\title{
Towards n-D Construction Visualization: Cost Integration into 4D Models
}

\author{
Katherine A. Liapi and Theodora Paschoudi \\ University of Patras \\ Greece
}

\section{Introduction}

Computer Aided Design, in addition to its use in the planning process, has often been used during construction in order to mitigate various problems. Taking into account that the major general problem the construction industry faces is constructability, or, otherwise, the ability to convert a design document into a real project, for a constructor, a proper design document is one that reflects an inherent knowledge of how the project will be built; that is, one that reflects the details that support the construction process and that includes sufficient information to avoid ambiguity and thus reduce claims and disputes. However, despite the fact that many contractors use 3D modeling to better visualize complex geometry, very often the capabilities of state-of-the-art 3D software are only marginally exploited during construction. Data that could be extracted from the model, or data that is already included in the software, is not used for solving constructability issues, developing or updating cost estimates etc; consequently many times data is re-entered in new and different formats wasting time and money. In other cases data is lost or corrupted resulting to loss of vital information.

In advanced project management processes, contractors can choose one construction plan over another based on construction process visualization (4D CAD). Yet, though 4D CAD models can provide invaluable information for the construction process, do not display information regarding the effect of alternative construction schedules on cash flows. Reversing the problem, although contractors have access to cost estimates, their usefulness in the constructability review process is really questionable since they do not reflect or highlight specific costs related to constructability issues.

Responding to the general need for visualization of building construction related information, the research discussed in this chapter focuses on the emerging need for displaying cash flow information in parallel with the construction sequence visualization.

\section{From 3D to $n-D$}

The increasing utilization of Information Technology applications in the construction industry is explained by the rising need for competitive and cost-efficient practices at a global level. (http://www.cmit.csiro.au/innovation/1998-08/pdf/innovation_ITconstruct. pdf). Information Technology in construction contributes primarily to improved planning, design, construction and maintenance methods. Computerized approaches to automate the 
planning process were proposed since the early nineties (Bennett \& Ditlinger 1994; Varghese \& O'Connor 1995). Accordingly Computer Aided Design (CAD) project models, specifications of the task, and other supportive non-graphical information had to be tightly integrated to fully describe planning situations in an interactive planning environment (Ling \& Haas, 1996).

In advanced management processes, contractors make use of 4D CAD models. Construction Sequence Visualization or Schedule Simulations display the progression of the construction over time by integrating 3D engineering data(CAD models) with a construction schedule. Practically a Schedule Simulation relates graphic model objects and schedule activity objects, and such models provide an effective decision making tool that can facilitate the construction of large scale complex projects. There are many state-of-the-art 4D software available for the construction industry such as the Bentley Navigator and PM Vision. With the use of $4 \mathrm{D} C A D$, project managers can create and update realistic schedules, rapidly resequence activities when necessary while reducing the risk of running out of space. Changes in the schedule are automatically updated by updating the design and schedule links.

Feedback from construction to the design team, resulting from $4 \mathrm{D}$ model reviews, leads to a more readily constructible, operable and maintainable project. 4D simulations and virtual reality techniques as part of a Detailed Planning Module can be used in order to allow site supervisors to visualize, rehearse, and develop construction plans (McKinney \& Fischer, 1998; Retik \& Shapira, 1999). 4D simulations have been shown to considerably improve the quality of construction plans and schedules (Lee et al. 2005). Examples of projects that benefited from the use of $4 \mathrm{D}$ CAD for Construction include the San Mateo County Health Facility, the Experience Music Project at Seattle, the Roof for Haas School of Business at UC Berkeley and others (Fischer \& Kam, 2003).

The capability and functionality of these applications are often limited when required to fully assist the generation of detailed execution plans; i.e. though $4 \mathrm{D}$ models can provide invaluable information for the construction process, information regarding the effect of alternative construction schedules on cash flows is scarcely supported. Specifically a $4 \mathrm{D}$ CAD model is not designed to support the time sequenced display of cost related information.

Since most 3D software allow for information exchange with innovative software used within the AEC industry, in recent state of the art applications the CAD model is not only used as a base for the $4 \mathrm{D}$ CAD model but also as an effective platform for the integration of more project parameters. Current methods of Construction Integrated Design do allow linking cost data to a 3D software, but most of the times such applications are data oriented, and do not support information visualization. Applications that take the concept of 3D computer modeling on an almost infinite number of dimensions, in order to address the entire life cycle of a construction project (Lee et al, 2002.) have also been developed. Such advanced applications do support cost integration and visualization and have been successfully applied to large scale projects (Fischer, 2005). However the costly and time consuming development of $4 \mathrm{D}$, n-D models, which are mostly in house developed by the research team, is often a serious drawback in the utilization of n-D automation processes. Finding personnel with the skills to develop the interface that connects the $4 \mathrm{D}$ model to the databases, as well as superintendents and foremen to operate all databases consist additional difficulties. 
Based on the above, a main objective of this research was to develop a simple application which could be used with most of the commercial software that support the development of 4D CAD models. Accordingly emphasis was placed on the development of an application that integrates material take-off with labor cost and takes advantage of the precision in quantity calculation resulting from detailed 3D models.

\section{Interoperability and IFC compliant software}

The International Alliance for Interoperability holds the leading edge in "collaborativedesign frameworks" that allow data transfer between building model software and analytic applications, including energy simulation, cost estimating, and construction scheduling. Indeed the main objective and task of the International Alliance for Interoperability (IAI), formed in 1994, was to define specifications for Industry Foundation Classes (IFC) to enable information sharing throughout the project lifecycle and across all disciplines and technical applications in the building industry (Staub-French \& Fischer, 2000). The Industry Foundation Classes, developed by IAI and defined as international standards for the building model data exchanging can be described as "a class library for Architecture, Engineering and Construction (AEC) objects" (IAI website, 2003). The first version of the IFC was released in 1995 and in subsequent years, many design software companies have added functionality to export IFC-based product models. The implementation of IFC specifications, available since late 1996, was very limited until the Building Lifecycle Interoperable Software (BLIS) project was conceived as a way to initiate the next phase in the widespread adoption of an object data model standard for the AEC/FM industry (BLIS, 2002).

The BLIS group that supported the implementation of IFC specifications in software products demonstrated software-interoperability among CAD design software, estimating, design spell-checking, code-compliance checking, production-schedule simulation (4D), and model-viewer applications (Khemlani, 2003). As IFC is non-proprietary and available globally to AEC/FM software developers, it enables interoperability among software applications, which means the end users in AEC/FM area can share the model data by IFC. This helped to make interoperability a reality for AEC firms, building owners and authorities that use IFC-compliant software (IAI, 2003). More recent efforts of the IAI are focusing on data share and seamless transfer of data between platforms and among applications so that each discipline contributes and withdraws information from the core model. As a result errors and omissions are reduced, and money and time are saved (IAI North America, 2003).

All major AEC CAD vendors such as Bentley's TriForma; Graphisoft's ArchiCad; Autodesk Architectural Desktop; Nemetschek AG's Allplan, Allplot, Allfem, and Allfa have been IFCcompliant already before 2000 (Staub-French \& Fischer, 2000). Working with AEC design software of multiple disciplines requires interoperability frameworks. One part of these interoperability frameworks relates to cross-file interchange of model geometry. These developments do not include though cost and schedule data in their interoperability framework, and are only part of larger interoperability concerns. A feature of IFC compliant software that is of primary importance for this research is that they support the generation of cost estimates and assist estimators with the maintenance of cost estimates throughout the project's life cycle changing the expectations of engineers from the existing cost estimating software. 
The evolution of the Internet and the ability to access the World Wide Web with fast connections tend to change the way that Construction Cost Estimating Software Systems (CCESS) are used. Current estimating software help estimators take off quantities automatically by taking advantage of the IFC concept and establishing an electronic link between a component in a 3D-product model and a cost item in a cost estimating database to create a cost estimate. On average, each item in a cost estimate is created seven times throughout the life of a project (Laitinen, 1998). Consequently, it is critical that IFC support the generation of cost estimates and also assist estimators by maintaining the cost estimates throughout the project life cycle (Staub-French et al, 2000).

A widescpread IFC compliant software available in the market is Timberline Estimating. It includes a CAD Integrator which incorporates support for the IFC standards thus becoming a useful tool to support cost estimators. Within the software environment a designer who uses IFC-compliant software, such as a CAD program, can save designs in IFC format. No additional measuring, digitizing, or manual takeoff is needed for the IFC objects. Should the design change, a new estimate can be generated in minutes. However, when the users need assistance in maintaining cost estimates throughout the project, the existing estimating software lack the necessary functionality. This problem is even more acute in the case of design changes. The reason is that construction costs are not only affected by material quantities but also by component properties (e.g. size and shape), and product features (e.g. repetition and openings) (Staub-French \& Fischer, 2000).

Except from the direct material cost deriving from a quantity take off, a cost estimate generally includes all costs related to site preparation, project financing costs, temporary facilities, project definition costs, insurance, acquisition/rent of land and property, taxes, project management, engineering costs, direct construction labor costs, quality assurance costs, start-up costs, escalation, contingency, operations and maintenance. Only direct material and labor cost are considered in the scope of this research.

\section{Cost integration into 4D models}

The research described in this chapter focuses on the development of an application that integrates material take-off with labor costs and takes advantage of the precision in quantity calculation resulting from the detailed 3D models (Paschoudi, 2003). The effort extends to the integration of the generated cash-flows within a 4D CAD model which animates the construction sequence by keeping the same timeline of the 4D CAD model.

The approach towards the fulfillment of this main objective is better described by the following sub-objectives that also reflect the process followed in this research:

- Identify methods to calculate the quantities and the cost of materials from the 3D model

- Identify methods to calculate the cost of resources (labor and engineering) from the resource loading on the schedule.

- Develop a method to generate a cash flow for materials and resources

- Develop a method to display the changes in the cash flow by keeping the same timeline of the 4D CAD model.

In order to generate the $4 \mathrm{D}$ model, information that originated from a 3D design needs to be combined with information developed from the scheduling. Since the schedulers in traditional project management do not develop the scheduling activities to accommodate the names and the ID's of the 3D model, the information provided for the development of the $4 \mathrm{D}$ model cannot be used without being first analyzed and appropriately modified. 
Essentially, during the development of the 3D model, data is entered on materials, simultaneously or later, while the scheduler creates his files based on 2D plans, or the work breakdown structure (WBS) provided by the contractor. Therefore, when the information for the generation of the 4D model is finally delivered, it often has to be re-entered or adjusted. Apparently, when a construction schedule simulation is produced, the information provided by the scheduler cannot be fully exploited because the resource loading he has already developed is not being used.

The developed method (Figure 1) reroutes the flow of information and benefits from this procedure by elaborating more data. Specifically the scheduler, instead of working independently for the development of the scheduling model, will first filter the information included in the 3D model, and then provide all necessary data for the development of the cash flow for materials and resources. The next step will be to integrate the cash flows into the $4 \mathrm{D}$ model and to visualize the changes in the cash flow while running the $4 \mathrm{D}$ model.

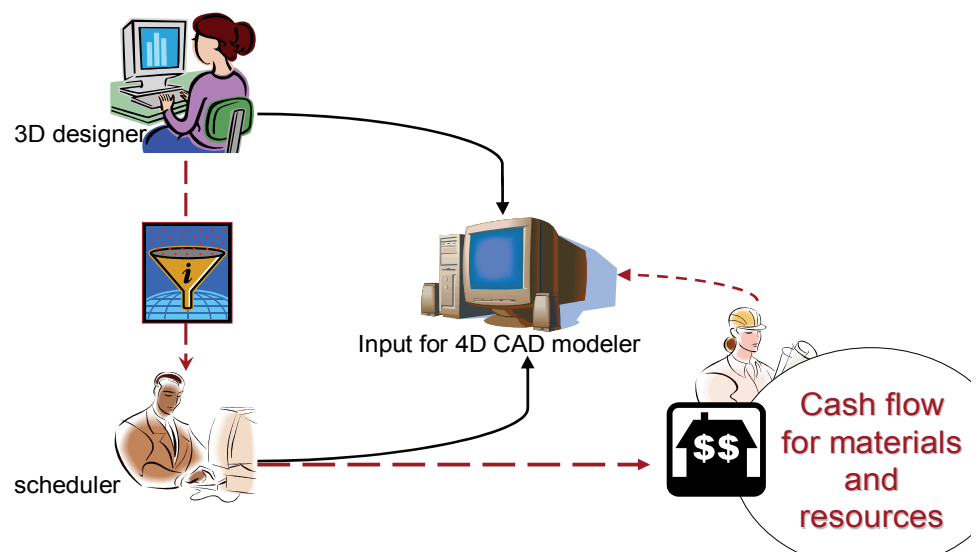

Figure 1. Standard vs. Proposed process for 4D modeling

The process consists of five basic steps:

STEP 1: Material take-off

STEP 2: Resource Loading

STEP 3: Generation of 4D model

STEP 4: Generation of cash flow for materials, labor and engineering costs

STEP 5: Visualization/Decision-making

Each step is further investigated and analyzed

\subsection{STEP 1: Material take-off}

This step leads to the generation of a bill of materials. In order to perform the quantity takeoff, the MicroStation TriForma has been used since: (a) allows for easy quantity take-off and (b) is compatible with commercially available $4 \mathrm{D}$ construction visualization software.

MicroStation TriForma, a software application for 3D solid modeling, is used to generate: a) "intelligent presentation drawings" (plans, building sections, elevations, details, perspectives) and b) quantification reports (material quantities, schedules, specifications, and cost estimates) from an integrated 3D project model. TriForma maintains the link 
between the model and all related documents and consequently once a change is made on the 3D model all the deriving documents update automatically. Practically, in TriForma all the information that needs to be tracked about a project can be inbuilt in the intelligent 3D model and extracted as presentation documents and/or as quantification reports .

The 3D model consists of objects that understand how to behave (e.g. a door can automatically cut the proper opening in a wall, and a form can be made to reshape its top to match the profile of another form). The dataset consists of intelligent pieces that reside in $\mathrm{xml}$ format and can be modified as regular text files. These text files are located in multiple directories. The directories are hierarchically structured within one main directory and the use of directories allows for use of the information from different users, in different computers and for more that one projects. Two of the most critical pieces of the MicroStation TriForma dataset are the parts and the components and are further described.

A part is a name given to all model elements that are intelligent when created and is linked to additional model and project information. The part definition serves in determining the symbology of the element at the time it was placed and in the extracted documents. In order to attach to a part supplementary information that concerns model materials, associated unit costs, and specifications it is necessary to attach a component. Components are linked to parts through a formula. Parts and components are both leveraged in the extraction of presentation materials and reports (TriForma User Guide, 2003).

The following sequence should be followed in order to generate a report:

- Build necessary families-parts-components

- Assign every element to be calculated to a part

- $\quad$ Link at least one component to every part that is assigned to an element

- $\quad$ Enter a valid Formula to every Component that is linked to a Part

As shown on the example in Figure 2, once a wall is designed, a part family is attached to it, and then a component family is specified (e.g. exterior, interior). By specifying the component, the unit of measurement, and the unit price that is used to apply material takeoffs are determined.

3D model element

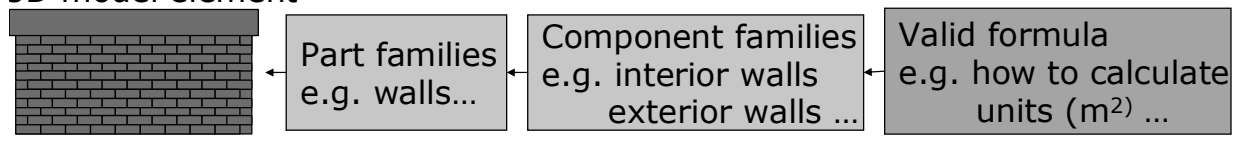

Figure 2. Generating the material take-off

The most important outcome from this step is the detailed report (in xls format) that contains all the quantities generated by each element in the 3D model (Table 1). The generated report in the Microsoft Excel file is dynamically linked to the model. "This link enables Element Selection and the creation of selection sets within the report. The model can then be opened within Excel to view the selection set of elements. The detailed report extracted from TriForma into Microsoft Excel file (Table 1) lists the quantities of the materials sorted first according to the component and then according to their IDs (e.g. the amount of cubic yards for every column). It can also list the unit price of the materials and finally the total cost per component. 


\begin{tabular}{|l|l|l|l|}
\hline Component number & ID & Quantity & Unit price \\
\hline Component 1 & 1 & q1 & p1 \\
\hline & 2 & q2 & p1 \\
\hline Component 2 & 3 & $\begin{array}{l}\text { Total for } \\
\text { component 1 }\end{array}$ & $\begin{array}{l}\text { Total for } \\
\text { component 1 }\end{array}$ \\
\hline & 4 & q4 & $\mathrm{p} 2$ \\
\hline & & $\begin{array}{l}\text { Total for } \\
\text { component 2 }\end{array}$ & $\begin{array}{l}\text { Total for } \\
\text { component 2 }\end{array}$ \\
\hline
\end{tabular}

Table 1. Report generated from MicroStation TriForma

\subsection{STEP 2: resource loading}

At the completion of this step the bill of labor costs is generated.

Primavera Project Planner, one of the most popular, powerful and widely used scheduling and cost estimating software by the AEC industry is used.

Scheduling software is broadly used in construction industry to facilitate effective management of projects. Practically it comprises part of the project controls defined as the process of planning, directing, and controlling the project from the start of construction through its completion. One of the essential concerns is that the information developed for the estimate should be presented in a way that can be easily used during the actual construction project (Feigenbaum, 2002). Material deliveries, equipment and people can all be managed through the schedule. Moreover advanced scheduling software are used for cost estimating as they allow for development of estimate information that can be easily used during the actual construction project. To generate cost estimates for labor costs the estimator/scheduler needs to have a completed quantity take-off, a list of crews and their activities, a list of crafts included in the crews, the wage rates for all of the crafts and the productivity rate for each crew (Feigenbaum, 2002). The efforts of these software focus basically on improving the resource management, cutting costs and making employee scheduling, room scheduling and shared equipment scheduling easy for everyone for companies of all sizes. Some of the features available include: simplicity of use, minimal server requirements, no need of additional software, web and browser based, remote access, day / week / month views for schedules, customizable time display, resource utilization and costing reports.

Most Construction Cost Estimating software companies have incorporated the spreadsheet functionality in their software. Spreadsheet interface, allowance for modification of the cost database, Open Database Connectivity (ODBC) with spreadsheet software, or even Construction Cost Estimating add-ins for spreadsheet software are very common in today's Construction Cost Estimating Software Systems (CCESS).

The following process clarifies the tasks the scheduler should perform while executing the resource loading, in order that the information provided by him can be used in the next steps:

- $\quad$ Retrieve the IDs of the elements from TriForma

- $\quad$ Add scheduling activities for all desired objects of the 3D model

- $\quad$ Add resources and their unit costs for each scheduling activity 
Ultimately the detailed report (csv) contains all labor and engineering costs for each activity/element of the 3D mode, and appears in the format shown in Table 2: for every resource, all the correspondent IDs are listed and then cost per ID is calculated for every resource.

\begin{tabular}{|l|l|l|l|}
\hline Resources & ID & Quantity & Unit price \\
\hline Labor & 1 & $\mathrm{q} 1$ & $\mathrm{p} 1$ \\
\hline & 2 & $\mathrm{q} 2$ & $\mathrm{p} 1$ \\
\hline Field Engineer & 1 & $\mathrm{q} 3$ & $\mathrm{p} 2$ \\
\hline
\end{tabular}

Table 2. Report generated from Primavera Project Planner

\subsection{STEP 3: generation of the 4D model}

For the generation of the 4D model, Bentley's Navigator was chosen as a state-of-the-art software that encompasses the concept of classes and is compatible with both Bentley's TriForma and Primavera Project Planner.

The schedule objects, as defined within Primavera Project Planner, are linked to the graphic objects that were previously created with Bentley's TriForma. The linking occurs through an interface that is easy and user friendly that enables creating, breaking, editing, and reviewing multiple relationship links between objects.

When a Schedule Simulation is being replayed, the Navigator obtains graphic or geometric data from the graphic object in the model. Then, in order to display the graphic object at the right time during the schedule simulation, the Navigator finds the link between the graphic model object and the corresponding schedule activity.

Another very important concept the Navigator encompasses, essential for creating the links between the graphical and the scheduling objects is the JSpace modeling, specifically, defined as the "general purpose object-oriented system for creating data files and interacting with the large and complex sets of data encountered in the architecture, engineering, and construction industry (AEC) (JSpace Class Editor manual, 2002).The class is the template used for the JSpace model and from its definition, the shape, structure, data storage, behaviors, and knowledge for an object of that class is provided. The class definitions are stored in files called class libraries, and can be organized into one or more libraries depending on the project.

Moreover, within the JSpace environment that allows for intelligent interfaces with CAD systems, such as MicroStation and AutoCAD, and with database systems, such as Microsoft Access, Oracle, and SQL Server, the project participants can work together and customize the environment and the applications. Besides, as shown in this step of the progress, JSpace is used for real-time visualization as it can integrate real-time visualization, animation, and simulation within the modeling environment. Different views of a 3D model are available with the use of multiple windows which additionally allow display and view in a wireframe or rendered display.

The OLE links enable to create JSpace schedule models by using data that is imported from external schedules. Whether new objects are added, or simply the properties of the existing objects are updated, an appropriate JSpace class must be used. For this purpose, two classes are provided in the standard class library, one for the Primavera Project Planner and one for the Microsoft Project: P3_activity class is designed for importing Primavera Project Planner schedule activities. 
Before linking the 3D model to the scheduling activities, in Figure 3, the following tasks must be completed:

- $\quad$ Extract the JSPACE model from Triforma and open it in Navigator

- Insert the activities from P3

- $\quad$ Create the new JSPACE model from P3

- $\quad$ Link the objects of the 3D model to the activities of the P3

Once the graphic objects are linked to the scheduling activities, the $4 \mathrm{D}$ model is automatically generated, and in the next step the cash flows are generated in order to integrate them in the $4 \mathrm{D}$ model.

\subsection{STEP 4: Generation of cash flow}

Once the material take-off and the resource loading are complete, the next goal is to generate the cash flow that includes the material and labor costs. The combination of this information since it is deriving from different software is not feasible with the currently available software.

Hence there is a need for the development of a new tool that will allow the merging of the two spreadsheet files and will generate the cash flows. Therefore a commercial software based application that allows for linking the labor costs with the material costs on a predefined timeline is developed. The conceptual approach and use of this application as part of the discussed process are explained in the following section.

A simple and user friendly application was developed to facilitate the needs of this step of the process as the files generated from MicroStation TriForma and Primavera Project Planner needed to be linked. The application is called TriVera (since it is combining files generated from TriForma and Primavera) and is written in Visual Basic. Basically it is an add-in for Microsoft Excel and can be easily installed (Figure 3).

The conceptual approach, shown in Figure 4, depicts the procedure repeated every time the application is used. First, the unique ID generated within TriForma for every element chosen to display is retrieved from the detailed report. This ID is used by the scheduler to schedule the respective activity. The two files are combined within TriVera to create a new Microsoft Excel file and then generate the cash flow

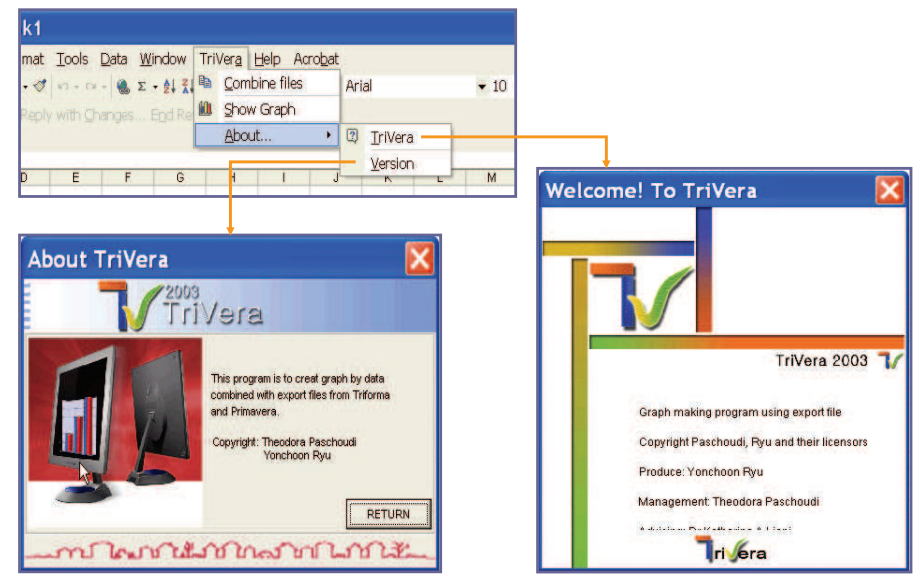

Figure 3. TriVera's menu interface 
The procedure performed by TriVera in order to create this new Microsoft Excel file is the following:

- The application defines the ID of the first scheduled activity listed in the first predefined time period (e.g. a week) in the file created from Primavera.

- This ID from the Primavera Excel file is matched with the ID in the TriForma Excel file and the cost of labor and materials is identified, respectively.

- $\quad$ Once the same procedure is repeated and completed for all the IDs listed under the first pre-defined period, the two types of costs are plotted on the cash flow output.

- The same procedure is repeated for every time period reflected on the cash flow.

It is important to note that the cost of material is credited at the beginning of the activity, while the cost of resources appears on the cash flow during the entire time required to complete the construction activity.

Once the cash flow is generated the next step focuses on its integration in the 4D model.

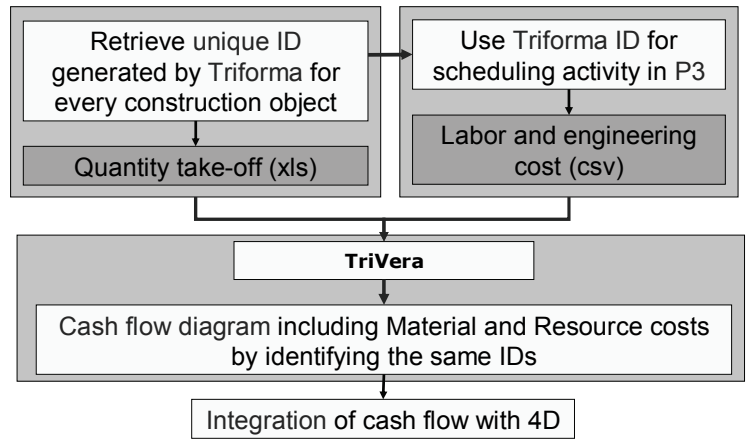

Figure 4. TriVera - Conceptual approach

\subsection{STEP 5: visualization/decision-making}

In this step the animation of the cash flows is generated establishing the integration of cost into the $4 \mathrm{D}$ model. A user friendly animation creation software, VEGAS, that creates animations from a series of picture files (gif, jpeg, bitmap etc) has been chosen.

Before using the animation creation software the user has to generate from TriVera all the necessary cash flows he desires to display simultaneously to the display of the 4D model. Once all the cash flows are generated for regular time frames throughout the progress of the project (Figure 5) then Vegas can be used and the next actions to be taken are:

- Define the timeline of the animation of the 4D CAD

- Use the same timeline for the animation of the cash flows

At this point of the research it s not possible to have the animation in the same screen as the $4 \mathrm{D}$ CAD display; the two animations are viewed on the same time but from different monitors.

\section{Case study: Dallas High Five}

In support of this research an important infrastructure project was chosen for a small scale application.

In 2002 the Texas Department of Transportation started the construction of a 5-level Interchange (intersection of I-635 and U.S. 75) to accommodate approximately 500,000 
vehicles per day. The cost of the project was estimated to $\$ 261$ Million. It started on January 2, 2002 and was scheduled to be completed in 2006. The so called "Dallas High Five" was a very challenging project as it had schedule and budget constraints and severe business impacts.
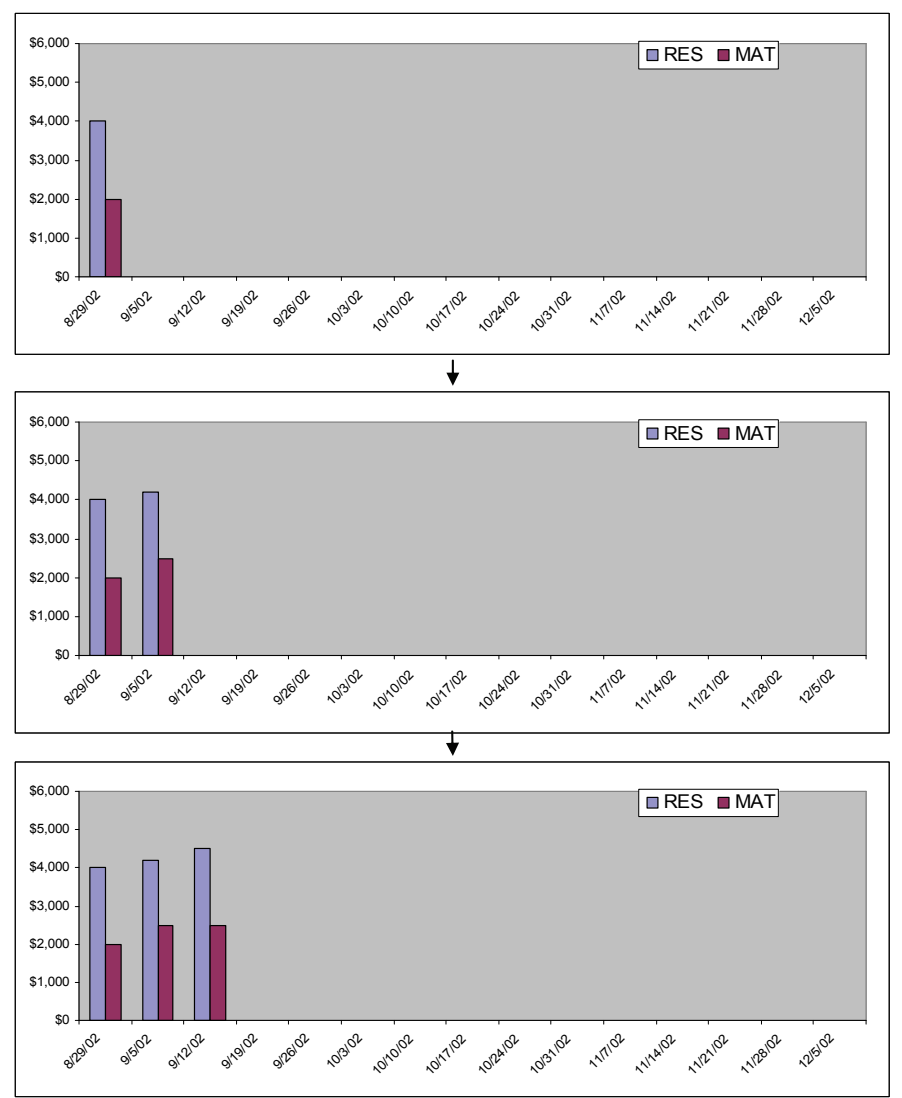

Figure 5. Cash flow animation

The continuously changing geometric configurations during its construction affected traffic planning decisions and complicate the overall project management. To facilitate decision making regarding both construction sequence and traffic planning, a visualization system that effectively uses 3D and 4D CAD technologies to support the planning, construction, and execution of the Dallas High Five project was proposed and developed by a UT research team (Liapi et al, 2003). A section of the project that was particularly complex in which the $4 \mathrm{D}$ helped a lot was the design for the Coit Road Bridge (Figure 6). The reconstruction of the Coit Road Bridge that had two lanes and two left-turn lanes in both directions was completed in August 2003. An important feature of the developed system was a comprehensive 3D database with three distinct levels of geometric configurations: a) current as-built, b) intermediate planned/as-built (including temporary structures), and c) final asdesigned. 


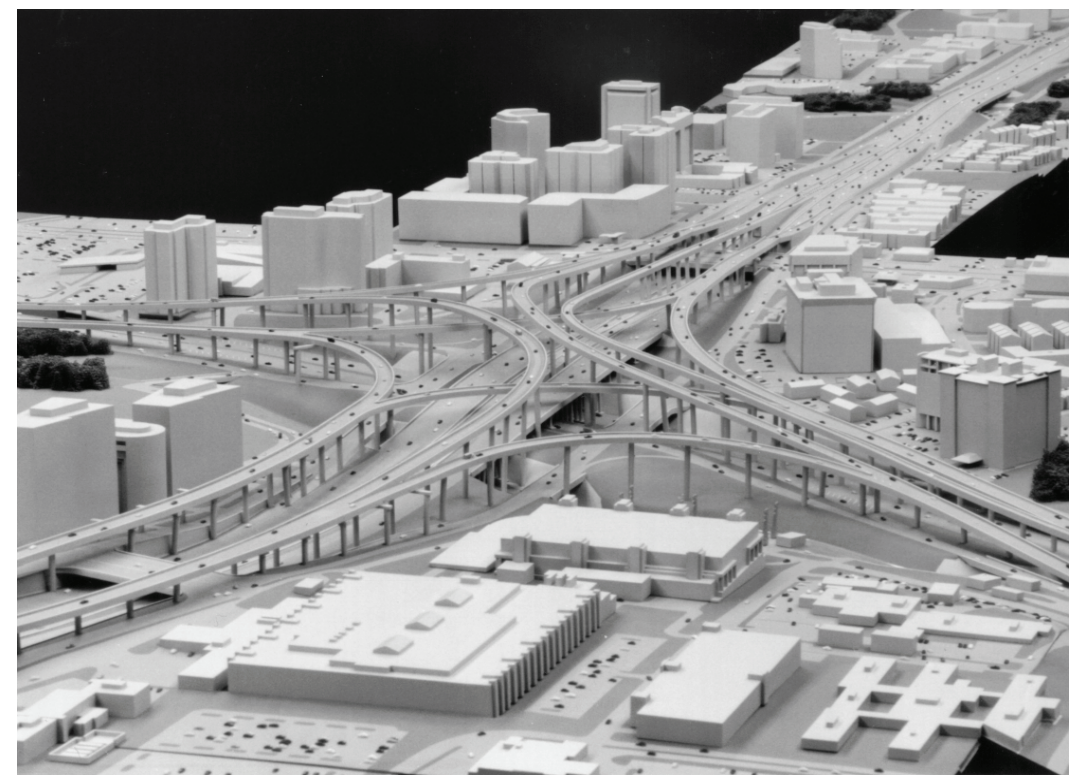

Figure 6. Dallas High Five interchange (source http:/ / www.dallashighfive.org. November 2003)

The development and usage of the $4 \mathrm{D}$ model to support construction improved communication between project teams (Department of Transportation Engineers, contractors or sub-contractors, etc.) by visually displaying alternative schedule and traffic plans during the construction of the project. The $4 \mathrm{D}$ CAD model provided the project's participants with a valuable visualization and decision making aid. An important feature of the $4 \mathrm{D}$ CAD model was that it integrated traffic planning which was of critical importance during construction (Liapi, 2003).

The developed 4D model, albeit a very useful and cost efficient tool, did not reflect the cost implications of alternative construction plans. Though for the specific case the cost was not a determinant factor, the project has been selected for demonstrating how costs could be taken and displayed, because of the overall interest it presents.

For the purpose of this research a simplified demonstration for some construction elements of the Coit Road Bridge is performed. So for the sake of this study, a part, a family and a component are attached to a set of cylindrical columns in the project. A component is attached to the columns including a formula that calculates volume in cubic meters for the quantity take-off. The IDs for every graphic object are displayed as well.

These IDs are then used for the creation of the Primavera Project Planner file. As shown in Figure 7 for every ID generated from TriForma for the Coit-side cylinders, an activity with the same ID and a short description is added in Primavera. In this case, since all the IDs shown are referring to columns, they all have the same description: cylinder column-coit.

Then, the necessary labor resources for every activity are uploaded in the Primavera Project Planner and the report is generated. Once the two spreadsheet files are generated, the TriVera application is used to combine them and create the cash flow diagram displayed in Figure 8. 


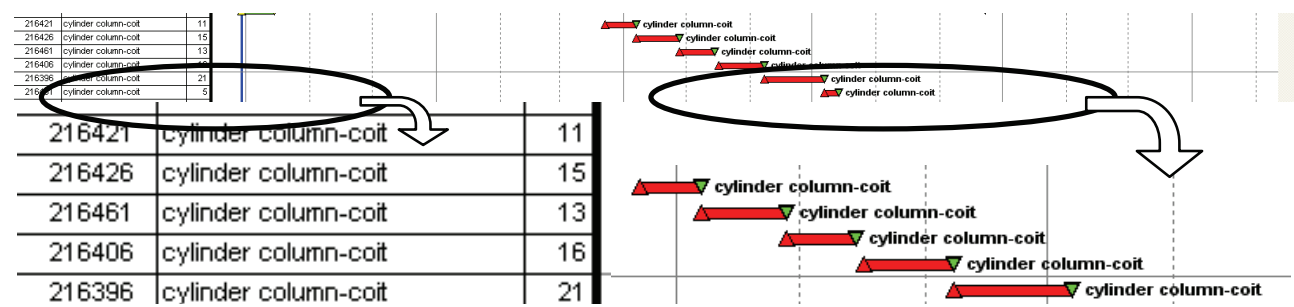

Figure 7. Activity scheduling in Primavera Project Planner

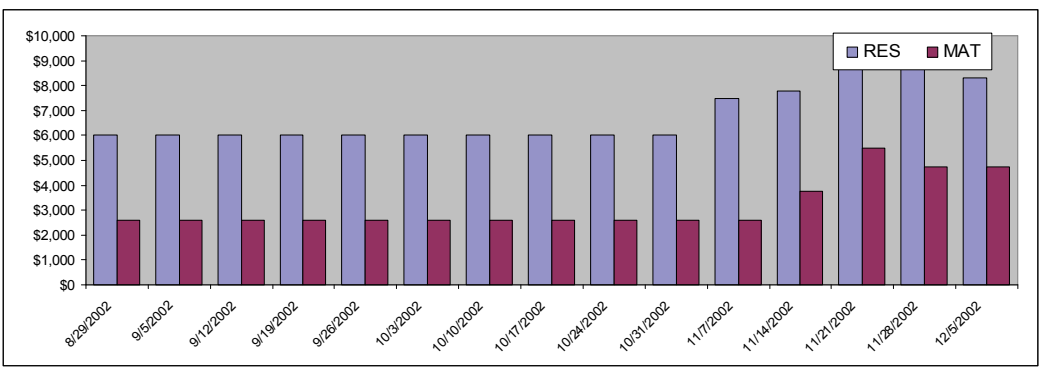

Figure 8. Cash flow generation within TriVera

In Figure 9, the final result is displayed. On the left side the $4 \mathrm{D}$ model is showing the animation of the two constructability scenarios and on the right side, and in reality on a different screen, the animation of the two corresponding cash flows is displayed. As a result the decision making process is enhanced with new tools that visualize the construction sequence and simultaneously allow for evaluation of the costs incurred.
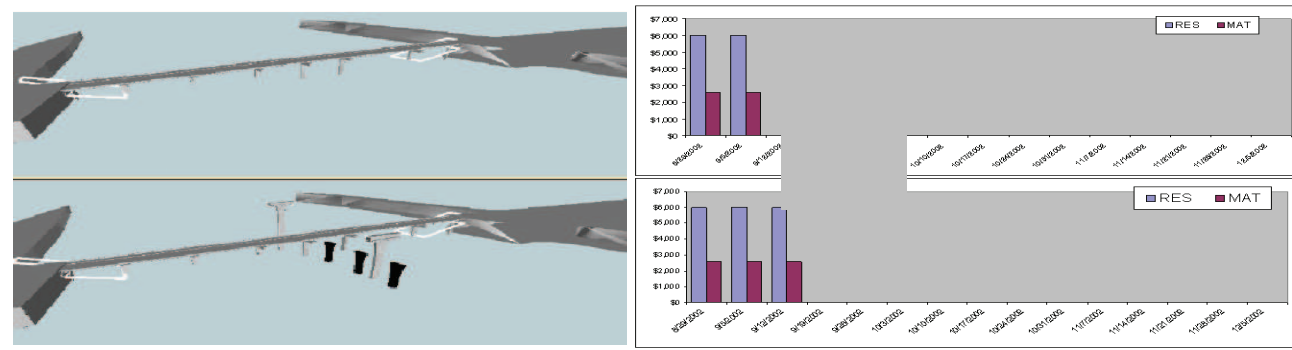

Figure 9. Two snapshots of the 4D model animation that display construction progress at the same time according to two different schedules and the respective cash flows.

\section{Conclusions and recommendations}

An efficient method for integrating cost to 4D CAD models for construction has been developed. A key feature of the method is a software application, TriVera, that facilitates the integration process and allows for the display of cost at the same time sequence as the construction schedule animation. The proposed method consists of a 5-step process that 
allows for easy development of cost estimates that can be used both for cost estimating and cost control.

The process provides the project participants, and primarily the project managers, with the ability to analyze and visualize multiple design alternatives in order to develop the most cost-effective and constructable solutions. It consequently allows for better control and decision making over different constructability issues and schedule scenarios, providing in this manner a linkage between constructability, $4 \mathrm{D}$, and cost estimating.

The time and the cost required for the development initially of the 3D model and sequentially the $4 \mathrm{D}$ model restrict the use of the process to projects with constructability and/or visualization issues. In these cases it is considered necessary for the understanding of the construction sequence and budget issues from all the project participants. Especially in large scale projects it can also facilitate the decision-making, allowing for faster authorization. The applications of this process include all civil works such as buildings, civil infrastructure and industrial projects. It could also be used both within an owner and a contractor organization while developing their cost estimates and/or reviewing constructability plans.

The anticipated benefits and the long term contributions of this research are expected to be numerous. The proposed process allows for improving the information exchange within the AEC industry by providing a better communication of building related information between the design and construction phases in a project. Since the scheduler uses the data generated by the designer, cost estimates become more accurate and margins for errors and omissions in schedule are reduced. Avoiding reentering data and filling the communication gaps, money and time are saved, as the information is directly received from the 3D model.

The proposed method addresses interoperability and brings the AEC industry one step closer to n-D CAD. Ultimately the proposed process for integrating cost into 4D models will contribute to the development of infrastructure methodologies and technologies that allow for the integration of construction parameters, such as buildability, accessibility, sustainability, and maintainability into the 3D model.

\section{References}

Bennet, C., and Ditlinger, S. (1994). Bechtel Automated Lift Planning System. Robotics for challenging environments. New York, N.Y.: ASCE, 1994.

Bjornsson, H. (2003) IT Revolutionises Construction. 1998. Building Innovation and Construction Technology. Available: http://www.cmit.csiro.au/innovation/199808/itrevolution.htm. October 2003.

Brown \& Root Braun. C.A.R.: Computer Aided Rigging Manual. Houston, TX.

Building Lifecycle Interoperable Software (BLIS) (2003). Blis Home Page. Available: http://www.blis-project.org/index2.html. November 2003

Dallas High Five (2003). Available: http:/ / www.dallashighfive.org. November 2003.

Elzarke, H. (2001). Computer Integrated Construction for Small and Medium Contractors. ASC 37th Annual Conference. Denver, Colorado, 255-62.

Feigenbaum, L. (2002). Construction Scheduling with Primavera Project Planner. Second ed. Upper Saddle River, N.J.: Pearson Education.

Fischer, M., and Kam, C. (2003) 4D Modeling Application Case Studies. SIENE Workshop on 4D modeling. Available: http://www.scpm.salford.ac.uk/ siene/ 4D\%20Application\%20Case\%20Studies-3.pdf. 
Gao, J. and Fischer, M. (2006). 4D CAD on Building Construction Projects: Benefits for Project Success and Controllable Implementation Factors, Construction Informatics Digital Library http:/ /itc.scix.net

Goldberg, H. E. (2003). Estimating Software Taps into Cad Building Model Data. CADALYST. Available: http://www.cadalyst.com/solutions/aectools/0902ae ctools/ 0902 aectools.htm. November 2003.

Gould, F. E., and Nancy E. J. (2003). Construction Project Management. Second ed. Upper Saddle River, N.J.: Pearson Education, 2003.

Holness, G. (2003). V.R. Smart IM for Project Man. January 2003. ASHRAE. Available: http:// www.leanconstruction.org/pdf/holness_1.pdf. November 2003.

IAI North America (2003). New Member Brief. 2003. Available: http://www.iai-na.org/ membership/membership_brief.php. November 2003.

International Alliance for Interoperability (2003). I.F.C. Resources. 2003. Available: http:// www.corenet.gov.sg/it_standards/iai/5_IFC_Resources.htm. November 2003.

Jspace Class Editor User Guide. Bentley, 2002.

Khemlani, L.(2003). Interoperability and the Solibri Model Checker. November 2002. CADENCE AEC Tech News. Available: http://www.cadenceweb.com/ newsletter/aec/1102_2.html. November 2003.

Lee, A., et al. (2002). Developing a Vision for an $\mathrm{nD}$ Modeling Tool, CIB w78 Conference. Aarthus School of Architecture, Denmark: International Council for Research and Innovation in Building and Construction, 2002.

Lee, A., Wu, S., Marshall-Ponting, A., Aouad, G., Tah, J., Cooper, R., and Fu, C. (2005) n- D modelling - a driver or enabler for construction improvement, RICS Research paper series , University of Salford,United Kingdom.

Liapi, K., Kwaja, N., O' Connor, J. (2003). Highway Interchanges: Construction Schedule and Traffic Planning Visualization, 2003 Transportation Research Board (TRB) Annual Meeting, Proceedings, Liapi January 18, 2003, Washington DC. CD ROM.

Liapi, K. (2003). 4D Visualization of Highway Construction Projects , IEEE, Seventh International Conference on Information Visualization, Proceedings, July 14-17, 2003, London, GB, 639-644.

Ling, K-L., and Haas, C.T. (1996). An Interactive Planning Environment for Critical Operations, Journal of Construction Engineering and Management, 212-22.

McKinney, K., and Fischer, M. (1998). Generating, Evaluating and Visualizing Construction Schedules with Cad Tools., Automation in Construction 7.6 , 433-47.

Microstation Triforma User Guide. Bentley, 2003.

Navigator User Guide. Bentley, 2003.

Paschoudi, Th.(2003). Cost Integration into 4D models, Thesis,University of Texas, at Austin.

Retik, A., and Shapira A. (1999). VR-Based Planning of Construction Site Activities. Automation in Construction 8.6 (1999): 671-80.

Saad, I.M., and Batie, D. (2002). The Science and Technology Building 4D Construction Model. 2002. Southeast Section Conference, ASEE. Available: http://www.ecu.edu / ciitr/ ASEE2002.pdf. December 2002.

Sanvido, V.E., and Madeiros, D.J. (1990). Applying Computer-Integrated Manufacturing Concepts to Construction, Journal of Construction Engineering and Management 116.2 (1990): 365-79. 
Sriprasert, E., and Dawood, N.(2001). Potential of Integrated Digital Technologies (IDT) for Construction Workforce Instruction, Conference at Chalmers, Gothenburg Sweden: AVR II, 2001. 136-45.

Staub-French, S., and Fischer, M. (2003). Practical and Research Issues Using Industry Foundation Classes, Center for Integrated Facility Engineering. Available: http:// www.civil.ubc.ca/faculty/Staub-French/index.html.November 2003.

Staub-French, S., and Fischer, M. (2000). Formalisms and Mechanisms Needed to Maintain Cost Estimates Based on an IFC Product Model. ICCCBE-VIII, Stanford University.

TIMBERLINE. Cad Integrator (2003). Available: http://www.timberline.com/include/ pdfs/cad_integrator.pdf. October 2003.

Tollefsen, T. \& Haugen, T. (2007). 3D AND 4D Modeling for Design and Construction coordination: Issues and lessons learned, EDITOR: B-C Björkhttp://itcon.org /2007/26/

TxDOT (2003). TxDOT's High Five Interchange Project Ahead of Schedule. August 2003. TxDOTExpressway. Available : http://www.dot.state.tx.us/dal/newsrel/ 058\%2D2003.htm. October 2003.

Vargese, K., and O'Connor, J.T.(1995). Routing Large Vehicles on Industrial Construction Site. Journal of Construction Engineering and Management 121.1 (1995): 1-12. 


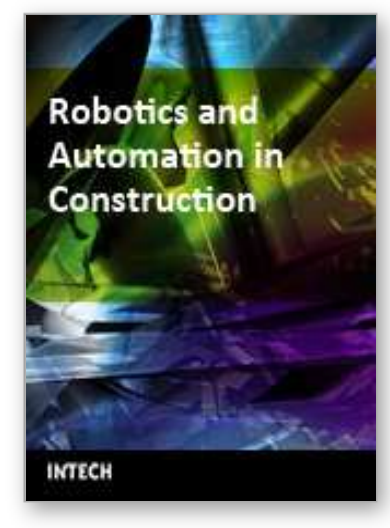

\author{
Robotics and Automation in Construction \\ Edited by Carlos Balaguer and Mohamed Abderrahim
}

ISBN 978-953-7619-13-8

Hard cover, 404 pages

Publisher InTech

Published online 01, October, 2008

Published in print edition October, 2008

This book addresses several issues related to the introduction of automaton and robotics in the construction industry in a collection of 23 chapters. The chapters are grouped in 3 main sections according to the theme or the type of technology they treat. Section I is dedicated to describe and analyse the main research challenges of Robotics and Automation in Construction (RAC). The second section consists of 12 chapters and is dedicated to the technologies and new developments employed to automate processes in the construction industry. Among these we have examples of ICT technologies used for purposes such as construction visualisation systems, added value management systems, construction materials and elements tracking using multiple IDs devices. This section also deals with Sensorial Systems and software used in the construction to improve the performances of machines such as cranes, and in improving Human-Machine Interfaces (MMI). Authors adopted Mixed and Augmented Reality in the MMI to ease the construction operations. Section III is dedicated to describe case studies of RAC and comprises 8 chapters. Among the eight chapters the section presents a robotic excavator and a semi-automated façade cleaning system. The section also presents work dedicated to enhancing the force of the workers in construction through the use of Robotic-powered exoskeletons and body joint-adapted assistive units, which allow the handling of greater loads.

\title{
How to reference
}

In order to correctly reference this scholarly work, feel free to copy and paste the following:

Katherine A. Liapi and Theodora Paschoudi (2008). Towards n-D Construction Visualization: Cost Integration into 4D Models, Robotics and Automation in Construction, Carlos Balaguer and Mohamed Abderrahim (Ed.), ISBN: 978-953-7619-13-8, InTech, Available from:

http://www.intechopen.com/books/robotics_and_automation_in_construction/towards_nd_construction_visualization_cost_integration_into_4d_models

\section{INTECH}

open science | open minds

\section{InTech Europe}

University Campus STeP Ri

Slavka Krautzeka 83/A

51000 Rijeka, Croatia

Phone: +385 (51) 770447

Fax: +385 (51) 686166

\section{InTech China}

Unit 405, Office Block, Hotel Equatorial Shanghai

No.65, Yan An Road (West), Shanghai, 200040, China 中国上海市延安西路65号上海国际贵都大饭店办公楼 405 单元

Phone: +86-21-62489820

Fax: +86-21-62489821 
www.intechopen.com 
(C) 2008 The Author(s). Licensee IntechOpen. This chapter is distributed under the terms of the Creative Commons Attribution-NonCommercialShareAlike-3.0 License, which permits use, distribution and reproduction for non-commercial purposes, provided the original is properly cited and derivative works building on this content are distributed under the same license. 